\title{
El Instituto del Paisaje de la Fundación Duques de Soria
}

El Instituto del Paisaje de la Fundación Duques de Soria se fundó en 1999, y tuvo su primera reunión formal el 22 de febrero de ese año. Dirigido, desde entonces, por Eduardo Martínez de Pisón, Catedrático de Geografía Física de la Universidad Autónoma de Madrid, y contando además con un coordinador y un secretario, su comité rector inicial se formó con nueve profesores universitarios y profesionales de distintas materias, todas ellas relacionadas directamente con el paisaje, que abarcaban los siguientes ámbitos: geografía, biología y ecología, cultura, urbanismo y paisajismo, ingeniería forestal y de obras públicas, aspectos jurídicos, planificación, política y gestión ${ }^{1}$. Los documentos fundacionales del Instituto definieron su sentido y sus intenciones en los siguientes términos:

«El estudio del paisaje en España posee tradición científica. Adquirió especial rigor en los años cuarenta en la Escuela Geográfica del profesor Manuel de Terán. Recientemente, ha multiplicado sus facetas y se ha diversificado a otras ciencias y

\footnotetext{
${ }^{1}$ Junto a Eduardo Martínez de Pisón (director), Concepción Sanz Herráiz (coordinadora) y Pedro Molina Holgado (secretario), geógrafos los tres, los miembros iniciales del comité rector, directamente relacionados con esos ámbitos en su dedicación intelectual y profesional, fueron los siguientes: Luis Felipe Alonso Teixidor (arquitecto), Miguel Arenillas Parra (ingeniero de Caminos, Canales y Puertos), Javier Castroviejo Bolíbar (biólogo) Josefina Gómez Mendoza (geógrafa), Nicolás Ortega Cantero (geógrafo), Juan Ruiz de la Torre (ingeniero de Montes), Leandro Silva del Moral (paisajista) y Jesús Vozmediano (jurista). Posteriormente, se incorporó al consejo rector María Medina Muro (paisajista).
} 
técnicas hasta constituir un campo de trabajo amplio y sólido, aunque tal vez disperso.

La actual amplitud de puntos de vista con que se aborda el estudio del paisaje no se ha reflejado en una mejora en la conservación y gestión de los valiosos paisajes españoles, debido en cierta medida a las lógicas limitaciones de la normativa española dedicada a la protección de espacios. Existe sin embargo un creciente interés en el paisaje, puesto de manifiesto en el seno del Consejo de Europa, donde se ha elaborado un documento de conservación y gestión de los paisajes, la Convención Europea del Paisaje.

El Instituto del Paisaje nace con un espíritu claramente integrador y con el interés de convertirse en centro de coordinación de los distintos y numerosos grupos existentes dedicados al estudio del paisaje en sus diversas facetas. Labor que sin duda se concretará en un adecuado entendimiento, gestión y protección de los paisajes españoles. Cuenta, por tanto, con la adscripción de esos grupos y profesionales para desarrollar un conjunto de actividades, coordinadas por la dirección y el comité rector del Instituto, si bien se entiende que el ejercicio real de estas actividades sólo se puede dar, claro está, en una acción libre.»

La actividad desarrollada por el Instituto del Paisaje de la Fundación Duques de Soria ha procurado poner en práctica sus intenciones fundacionales. Se ha relacionado regularmente, por ejemplo, con otros grupos y profesionales interesados en el paisaje, y esas relaciones se han concretado en diversas colaboraciones en los seminarios organizados por el Instituto y en las publicaciones consiguientes. La relación con el Observatorio del Paisaje de Cataluña, y con su director, Joan Nogué, es una muestra de ello, lo mismo que la mantenida con varios profesores de las Universidades francesas de Pau y Burdeos, pertenecientes al Laboratorio SET (Société, Environnement, Territoire), vinculado al CNRS y a la primera de las Universidades mencionadas. Otras relaciones se han concretado individualmente, con profesores y profesionales españoles y extranjeros. Y también se ha ocupado el Instituto, por añadir otro ejemplo, de promover actividades encaminadas, en unos casos, a mejorar el conocimiento de los paisajes españoles (en especial, los sorianos), y, en otros, a favorecer, sobre todo a través de informes, su adecuada valoración y protección.

Una de las vertientes principales de la labor del Instituto es la organización de un Seminario anual, durante una semana del mes de julio, en la sede soriana de la Fundación, el Convento de la Merced, dedicado a exponer y debatir aspectos relacionados con su cometido. El Instituto tuvo como precedente tres Seminarios de Medio Ambiente, dirigidos por Eduardo Martí- 
nez de Pisón, ya dedicados al paisaje, uno en su relación con el medio, el segundo sobre paisajes de montaña y el tercero sobre la protección de los paisajes $^{2}$.

FIGURA 1

\section{EXCURSIÓN DE 2006, DIRIGIDA POR EL PROFESOR MUÑOZ JIMÉNEZ. EN MURO DE ÁGREDA}

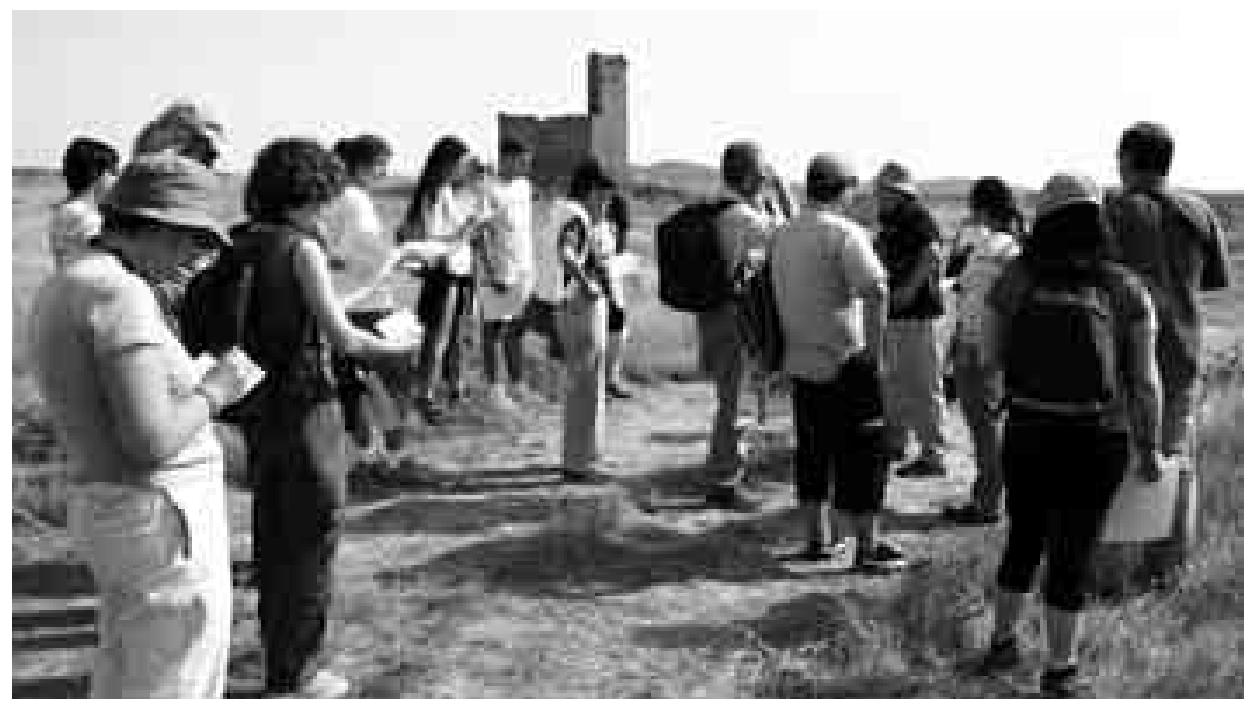

Tras la fundación del Instituto, durante los tres primeros años (1999, 2000 y 2001), se mantuvo el planteamiento del anterior Seminario de Medio Ambiente, desarrollado mediante lecciones y coloquios, distinto, como veremos luego, del que se promovió después, cuando pasó a llamarse Seminario del Paisaje. Organizados en forma de trilogía, y previstos con anterioridad a esa fundación del Instituto (lo que explica su mantenimiento), los tres Seminarios fueron dirigidos por Florencio Zoido Naranjo, Catedrático de Análisis Geográfico Regional de la Universidad de Sevilla, y, con el título conjunto de «Paisaje y ordenación del territorio», se trataron sucesivamente en ellos variados

2 Martínez de Pisón, 1998; Martínez de Pisón y Sanz Herráiz, 2000. El primer libro recoge los resultados del Seminario de 1996, y el segundo, los de los desarrollados en 1997 y 1998. 
aspectos relacionados con el conocimiento y la evaluación de los paisajes, con su protección y gestión, y, por último, con lo que atañe a la planificación y los proyectos de ordenación con contenido paisajístico. Los resultados de estos Seminarios, en los que participaron más de cuarenta profesores y cerca de ciento cincuenta alumnos, se publicaron conjuntamente (Zoido y Venegas, 2002).

Tras un año de paréntesis, se planteó un nuevo modo de entender el Seminario, al tiempo que el término «Paisaje» sustituyó al anterior de «Medio Ambiente» en su denominación, expresándose también de esa manera el renovado énfasis paisajístico que lo caracterizó desde entonces. Pasó a concebirse como un Seminario de investigación, en el que participa un número reducido (nunca superior a treinta) de profesores y estudiantes avanzados, preferentemente de doctorado, incluyendo a los ponentes y a los comentaristas. Se redujo el número de ponentes y se amplió considerablemente el tiempo de los debates dedicados a las ponencias, en consonancia con el nuevo planteamiento del Seminario, cuya finalidad se centra en el intercambio de ideas y opiniones, no en la simple exposición magistral, y su organización responde a esa intención. Todos los participantes disponen de las ponencias con antelación, de modo que puedan leerlas con el debido detenimiento, y los ponentes exponen en las sesiones del Seminario una síntesis de los trabajos aportados, con los aspectos que consideran más significativos, para pasar después al debate. Dos aspectos más completan el contenido del Seminario: además de las ponencias, se exponen y discuten también las comunicaciones elaboradas por los asistentes, que son previamente propuestas por sus autores y aceptadas por la dirección del Seminario; y se realiza una excursión directamente conectada con los temas abordados en cada caso, recuperando así una arraigada tradición geográfica que sigue siendo, por muchos motivos, sumamente valiosa.

Una vez modificado su enfoque en los términos señalados, Nicolás Ortega Cantero, Catedrático de Geografía Humana de la Universidad Autónoma de Madrid, dirigió los tres primeros Seminarios, los de los años 2003, 2004 y 2005. Se planteó en ellos un acercamiento al paisaje que procuró tener en cuenta las diversas y complementarias dimensiones (científicas y artísticas, explicativas y comprensivas) puestas en juego, y se habló sucesivamente en esos años de los componentes naturales y culturales del paisaje, de sus conexiones con la memoria histórica y la identidad nacional, y de sus imágenes de variado signo, desde las literarias y pictóricas, hasta las cartográficas y geográficas. Con todo ello se procuró ofrecer un tratamiento progresivo y argumentalmente vertebrado del significado del paisaje en el horizonte intelectual de la 
modernidad. Tres excursiones, dirigidas por Julio Muñoz Jiménez, profesor titular de Geografía Física de la Universidad Complutense de Madrid, acompañaron a estos tres Seminarios: «El paisaje de la Sierra de Pela» (2003), «Campos, "tierras altas", valles y montañas en la visión cultural del paisaje soriano» (2004), y «Las formas tabulares en la imagen del paisaje soriano: sierras llanas, altos y parameras» (2005). Estos Seminarios se han publicado -incluyendo las ponencias y algunas de las comunicaciones presentadas, y además el texto de apoyo de la tercera excursión- en tres libros sucesivos, coeditados por la Universidad Autónoma de Madrid y la Fundación Duques de Soria ${ }^{3}$.

Concluida la trilogía anterior, el Seminario del Paisaje pasó a ser dirigido conjuntamente por Eduardo Martínez de Pisón y Nicolás Ortega Cantero, manteniéndose, por lo demás, la orientación seguida en las ediciones precedentes. Concebidos, al igual que aquéllos, como un conjunto coordinado, los tres Seminarios siguientes, desarrollados en 2006, 2007 y 2008, se dedicaron sucesivamente a tratar de la presencia y la conservación del paisaje en los Parques Nacionales, de las experiencias de recuperación de las que ha sido objeto en diversos campos intelectuales y profesionales, y, finalmente, de los variados valores que se le atribuyen. Las tres excursiones correspondientes, que dirigieron Julio Muñoz Jiménez y Francisco Alonso Otero, profesor titular de Geografía Física de la Universidad Autónoma de Madrid, ofrecieron los siguientes contenidos: «Veruela y el Parque Natural del Moncayo» (2006), «Tres paisajes protegidos del Occidente soriano: Calatañazor y su entorno rural, el Burgo de Osma y su casco histórico y el Cañón del Río Lobos» (2007), y «Los paisajes sorianos de Machado» (2008). Las ponencias de estos Seminarios, junto a los textos de apoyo de las dos últimas excursiones, han sido publicados, como los anteriores, por la Universidad Autónoma de Madrid y la Fundación Duques de Soria4.

En las seis ediciones del Seminario del Paisaje que acabamos de mencionar, desarrolladas entre 2003 y 2008, participaron, como ponentes, comentaristas o comunicantes, geógrafos de las Universidades españolas que siguen: Universidad Autónoma de Madrid (además de Eduardo Martínez de Pisón y Nicolás Ortega Cantero, directores de los Seminarios, Josefina Gómez Mendoza, Concepción Sanz, Francisco Alonso, Elia Canosa, Emilia Martínez Garrido, Ma-

\footnotetext{
3 Ortega Cantero (ed.), 2004; 2005; 2006. Sobre los dos últimos de estos tres libros -Paisaje, historia y nación e Imágenes del paisaje - , pueden verse los comentarios dedicados a ellos respectivamente por Brandis (2007, pp. 388-390) y García Álvarez (2007, pp.390-394).

${ }^{4}$ Martínez de Pisón y Ortega Cantero (eds.) 2007; 2008; 2009. Sobre estos tres libros, puede verse la reseña de García Carballo (2009, pp. 454-456).
} 
FIGURA 2

EXCURSIÓN DE 2007, DIRIGIDA POR LOS PROFESORES ALONSO OTERO Y MUNOOZ JIMÉNEZ. EN EL MIRADOR GALIANA, SOBRE EL CAÑÓN DEL RÍO LOBOS

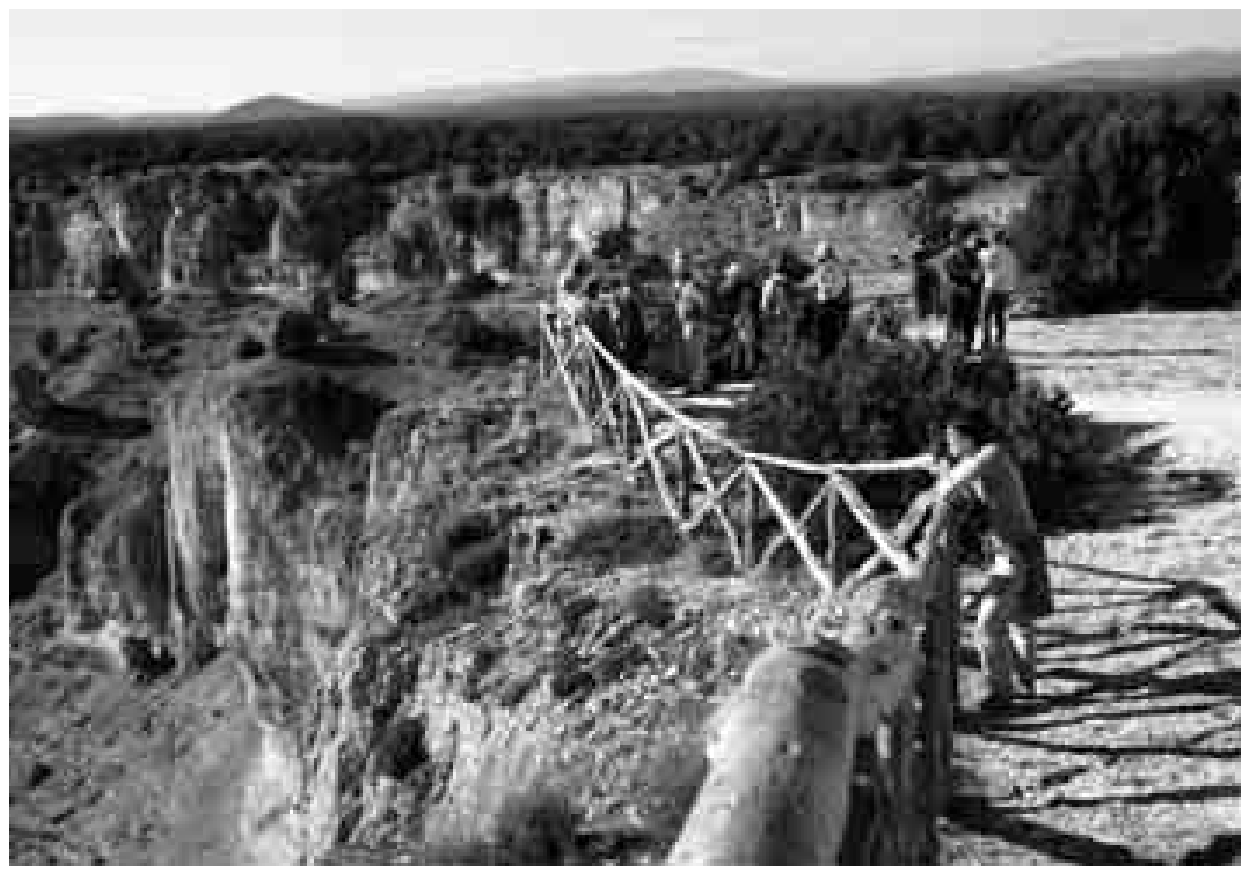

nuel Mollá y Ester Sáez Pombo), Universidad Complutense de Madrid (Dolores Brandis, Julio Muñoz e Isabel del Río), Universidad Carlos III de Madrid (Guillermo Morales y Jacobo García Álvarez), Universidad de Barcelona (Joan Tort y Valerià Paül), Universidad de Cantabria (Manuel Frochoso), Universidad de Córdoba (Antonio López Ontiveros, José Naranjo y Luisa Ramírez López), Universidad de Gerona (Joan Nogué, director del Observatorio del Paisaje de Cataluña), Universidad de La Laguna (M. Eugenia Arozena y Carmen Romero Ruiz), Universidad de Oviedo (Francisco Quirós, Felipe Fernández García y Juan Carlos Castañón), Universidad Pablo de Olavide de Sevilla (Juan F. Ojeda), Universidad de Salamanca (Valentín Cabero) y Universidad de Valencia (Joan F. Mateu).

A ellos se añadieron otros geógrafos de Universidades extranjeras: Hélène Saule-Sorbé, Jean-Yves Puyo, Isabelle Degrémont y Danièle Laplace- 
Treyture, todos ellos vinculados al Laboratoire Société, Environnement, Territoire (CNRS), y profesores en las Universidades de Burdeos y Pau, Didier Mendibil, miembro del equipo Épistémologie et histoire de la géographie (CNRS) que dirige en París Marie-Claire Robic y profesor del Institut Universitaire de Formation de Maîtres de Créteil, y Marcella Schmidt di Friedberg, profesora de la Universidad de Milán Bicocca. Y han participado igualmente, por último, profesores de otros ámbitos y profesionales relacionados con el paisaje: Antonio Morales Moya y Mariano Esteban de Vega, profesores de Historia Contemporánea en las Universidades Carlos III de Madrid y de Salamanca, Javier Maderuelo, profesor de Arquitectura del Paisaje de la Universidad de Alcalá y responsable de los programas y cursos del Centro de Arte y Naturaleza (CDAN) de la Fundación Beulas, Daniel Zarza, profesor de Urbanismo en esa misma Universidad, Miguel Aguiló, profesor de Arte y Estética de la Ingeniería en la Universidad Politécnica de Madrid, y la paisajista María Medina.

\section{FIGURA 3}

EXCURSIÓN DE 2008, DIRIGIDA POR EL PROFESOR ALONSO OTERO. EN GORMAZ

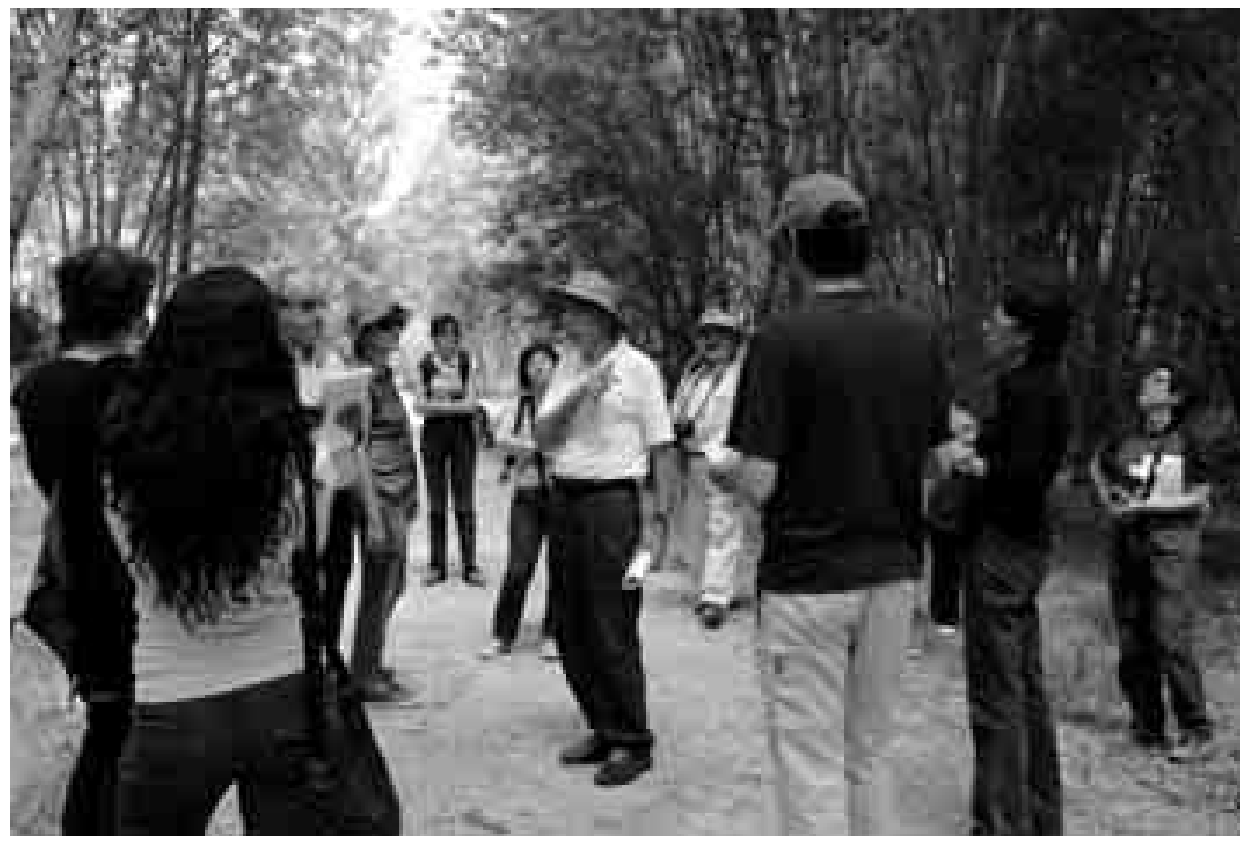

Estudios Geográficos, Vol. LXXI, 269, pp. 677-685, julio-diciembre 2010 ISSN: 0014-1496, eISSN: 1988-8546, doi: 10.3989/estgeogr.201023 
La incidencia de la crisis económica obligó después, a partir de 2009, a reducir temporalmente la envergadura de estos Seminarios. El de ese año, titulado «El paisaje: valores e identidades», que se encuentra en curso de publicación, tuvo una duración menor y sus ponencias corrieron a cargo de profesores de las Universidades madrileñas. Y en 2010, en lugar del Seminario, se ha organizado, en el Palacio de los Águila de Ciudad Rodrigo, sede de la Delegación de la Fundación Duques de Soria en esa ciudad, un Encuentro luso-español sobre el patrimonio paisajístico.

Por otra parte, además del Seminario del Paisaje el Instituto ha organizado alguna otra reunión de similar contenido, aunque con otra forma de organización. Poco después de su fundación, se desarrollo durante tres días, en mayo de 2000, en el Convento de la Merced de Soria, un Encuentro sobre «Historias del paisaje», dirigido por Nicolás Ortega Cantero, en el que participaron, como ponentes e invitados, investigadores de diversos campos (geografía, historia, historia de la economía, historia del arte, arquitectura, ingeniería) y algunos profesionales. También en este caso se publicaron las ponencias presentadas (Ortega Cantero, 2002).

Junto a la labor del Seminario, el Instituto ha desarrollado también, desde 2006, otra actividad de carácter más práctico: los Talleres de Paisaje, dirigidos por Concepción Sanz Herráiz, y asesorados por Eduardo Martínez de Pisón. Su finalidad es elaborar un catálogo de los paisajes de Castilla y León, comenzando por el de la provincia de Soria, y responden a una doble intención investigadora y docente. La investigación se desarrolla de forma regular a lo largo del año, elaborando sucesivos informes parciales, y la parte dedicada a la docencia se lleva a cabo, durante una semana (en julio o septiembre), en la sede soriana de la Fundación, donde los encargados del trabajo investigador presentan los resultados obtenidos a un número reducido de alumnos, al tiempo que los introducen, con algunas salidas al campo, en las formas de trabajo utilizadas.

Estas son, en fin, las principales actividades desarrolladas por el Instituto del Paisaje de la Fundación Duques de Soria a lo largo de sus poco más de diez años de vida. La elaboración de algunos informes sobre lugares paisajísticos de interés, a veces afectados por operaciones de conservación o restauración, se ha añadido ocasionalmente a su quehacer. Con todo ello, el Instituto ha logrado convertirse en uno de los principales núcleos intelectuales dedicados en España a estudiar el paisaje y a promover el necesario respeto a sus valores de diversa índole (natural y cultural). Sería deseable, y así se ha expresado en varios de los seminarios mencionados, que, en el futuro, la continuidad de esa labor del Instituto se viera además reforzada por la coordinación efectiva con 
otros grupos o instituciones igualmente interesados en la consideración teórica y práctica del paisaje.

\author{
Nicolás Ortega Cantero \\ Universidad Autónoma de Madrid
}

\title{
BIBLIOGRAFÍA
}

Brandis, D. (2007): “Paisaje, historia y nación”, Ería, 73-74, pp. 388-390.

García Álvarez, J. (2007): "De artistas-geógrafos y geógrafos-artistas: seis estudios sobre la iconografía moderna del paisaje", Ería, 73-74, pp. 390-394.

García Carballo, Á. (2009): "La labor del Instituto del Paisaje de la Fundación Duques de Soria”, Boletín de la Asociación de Geógrafos Españoles, 51, pp. 454-456.

Martínez de Pisón, E. (dir.) (1998): Paisaje y medio ambiente. Valladolid, Universidad de Valladolid y Fundación Duques de Soria, 152 pp.

Martínez de Pisón, E. y Sanz Herráiz, C. (eds.) (2000): Estudios sobre el paisaje. Madrid, Universidad Autónoma de Madrid y Fundación Duques de Soria, 368 pp.

Martínez de Pisón, E. y Ortega Cantero, N. (eds.) (2007): La conservación del paisaje en los Parques Nacionales. Madrid, Universidad Autónoma de Madrid y Fundación Duques de Soria, $242 \mathrm{pp}$.

Martínez de Pisón, E. y Ortega Cantero, N. (eds.) (2008): La recuperación del paisaje. Madrid, Universidad Autónoma de Madrid y Fundación Duques de Soria, 311 pp.

Martínez de Pisón, E. y Ortega Cantero, N. (eds.) (2009): Los valores del paisaje. Madrid, Universidad Autónoma de Madrid y Fundación Duques de Soria, 322 pp.

Ortega Cantero, N. (ed.) (2002): Estudios sobre historia del paisaje español. Madrid, Universidad Autónoma de Madrid, Fundación Duques de Soria y Los Libros de la Catarata, 186 pp.

Ortega Cantero, N. (ed.) (2004): Naturaleza y cultura del paisaje. Madrid, Universidad Autónoma de Madrid y Fundación Duques de Soria, 221 pp.

Ortega Cantero, N. (ed.) (2005): Paisaje, memoria histórica e identidad nacional. Madrid, Universidad Autónoma de Madrid y Fundación Duques de Soria, 294 pp.

Ortega Cantero, N. (ed.) (2006): Imágenes del paisaje. Madrid, Universidad Autónoma de Madrid y Fundación Duques de Soria, 332 pp.

Zoido Naranjo, F. y Venegas Moreno, C. (coords.) (2002): Paisaje y ordenación del territorio. Sevilla, Junta de Andalucía (Consejería de Obras Públicas y transportes) y Fundación Duques de Soria, 353 pp. 